\title{
CARLOS FIOLHAIS
}

Coordenaç̃o

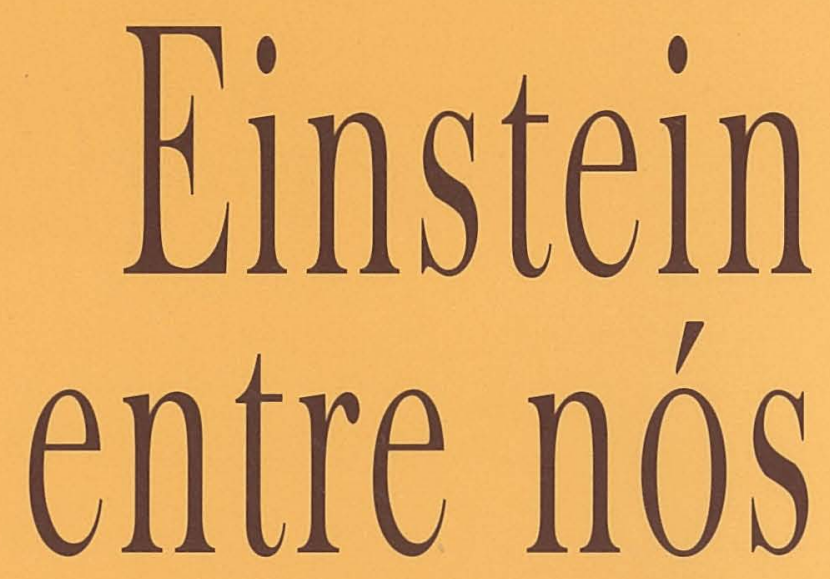

A recepcão de Einstein em Portugal

de 1905 a 1955

Coimbra Imprensa da Universidade $\quad 2005$ 
(Página deixada propositadamente em branco) 


\section{CARLOS FIOLHAIS}

Coordenação

\section{Einstein entre nós}

A recepscão de Einstein em Portugal

de 1905 a 1955

Coimbra I I prensa da Universidade $\quad 2005$ 


\section{Coordenação editorial}

Imprensa da Universidade de Coimbra

\section{Concepção gráfica}

António Barros

\section{Digitalização de imagens}

Alexandre Ramires

Museu de Ciência da Universidade de Lisboa

Paginação

SerSilito

\section{Execução gráfica \\ SerSilito - Maia}

\section{ISBN}

972-8704-60-7

\section{Depósito legal \\ 233349/05}

Outubro de 2005

(C) 2005, Imprensa da Universidade de Coimbra

\section{Apoios:}

Departamento de Física da Faculdade de Ciências e

Tecnologia da Universidade de Coimbra

Sociedade Portuguesa de Física

Associação para o Desenvolvimento do Departamento de Física (ADDF)

Programa Operacional Ciência e Inovação 2010

Museu de Ciência da Universidade de Lisboa 


\title{
Melo e Simas \\ O PORTUGUÊS QUE TESTOU EINSTEIN
}

\author{
Joaquim Fernandes ${ }^{(*)}$
}

Sabe-se que a abordagem inaugural dos princípios relativistas foi feita, entre nós, pela filosofia anti-positivista, de fundo espiritualista, de Leonardo Coimbra, a partir de 1912, na obra $O$ Criacionismo - onde insere, pela primeira vez, as equações da Relatividade restrita - e nas páginas da revista portuense Águia, órgão da Renascença Portuguesa.

Uma experiência pioneira, bastante divulgada, considerada fulcral para a confirmação experimental de um dos postulados relativistas, teve lugar em 1919, por ocasião do eclipse solar total de 29 de Maio e mobilizou duas expedições de astrónomos britânicos: uma, seguiu para a localidade de Sobral, no Brasil, a outra instalou-se na ilha do Príncipe, então sob domínio português. Aqui, o chefe da missão, Sir Arthur Eddington, colega de Einstein, esperaria ver a seu lado colegas portugueses. Mas o único sinal da contrapartida lusitana haveria de ser dado pelo jornal $O$ Século, de 24 desse mesmo mês, que noticia na sua primeira página a deslocação dos cientistas ingleses à pequena ilha. A investigação, como se sabe, tratava de registar o eventual desvio da luz das estrelas por interposição do campo gravitacional do Sol. Apesar das más condições atmosféricas, os resultados foram considerados válidos, tal como os das observações brasileiras de Sobral, certificando uma das teses mais popularizadas do físico alemão.

(*) Universidade Fernando Pessoa. 
A ausência dos astrónomos portugueses da campanha de observação do eclipse solar, de 1919, na Ilha do Príncipe foi, em parte, colmatada pelo trabalho, até hoje silenciado, do astrónomo Manuel Soares de Melo e Simas, ministro da Instrução Pública no governo chefiado por Ginestal Machado, em 1923.

Foi precisamente nesse mesmo ano, em 7 de Maio, no decurso da observação da ocultação da estrela «Washington 5478» pelo planeta Júpiter, que Melo e Simas, então subdirector do Observatório da Ajuda, ensaiou a comprovação das teses einsteinianas, procurando saber se das posições do planeta relativamente à estrela de comparação, determinadas antes da imersão e depois da emersão, se notaria qualquer diferença que pudesse ser explicada pela teoria da relatividade. Os resultados, não sendo indiscutíveis, revelaram ao astrónomo que essas divergências se teriam dado precisamente no sentido preconizado pelas teorias de Einstein. Ou seja, quatro anos depois, Melo e Simas compensou o desinteresse dos seus pares, oficialmente mais responsáveis, em acompanhar a missão de Arthur Eddington à então colónia portuguesa.

Importa recordar que os impactos iniciais das ideias relativistas, antes e depois de Einstein, haviam já mobilizado cultores de diferente formação, entre filósofos, biólogos e matemáticos, com destaque para o pioneirismo do filósofo Leonardo Coimbra e do militante republicano Basílio Teles, ambos portuenses. A revista Águia, dirigida por Teixeira de Pascoaes acolhe, a partir de 1912, textos do primeiro que irão compor o essencial do seu livro " $O$ Criacionismo”, onde transcreve pela primeira vez, entre nós, as equações da Relatividade restrita.

Decisiva para a consagração oficial das ideias de Einstein viria a ser o I Congresso da Associação Portuguesa para o Progresso da Ciência, celebrado em 1921, no Porto. Pela voz dos seus confrades espanhóis os nossos matemáticos começam, enfim, a prestar atenção às novas teorias sobre as dimensões do espaço e do tempo. A partir da década de 1930, a controvérsia entre partidários e adversários da Relatividade transfere-se para as revistas culturais da época, casos da Seara Nova ou do Sol Nascente, que acolher textos de Abel Salazar, Bento de Jesus Caraça, Ruy Luís Gomes, Gago Coutinho, entre outros, a pretexto das novas teorias, estimulando também a intervenção dos nossos físicos.

De uma forma indirecta, o nosso país ficou associado ao nome e às teses de Albert Einstein, mormente às etapas de verificação experimental de uma das suas hipóteses científicas, previstas no âmbito da Teoria da Relatividade: a curvatura da luz desviada pelo campo gravitacional de um corpo celeste. 
(Página deixada propositadamente em branco) 


\section{Série}

\section{Documentos}

Imprensa da Universidade de Coimbra

Coimbra University Press

2005

- U

C - 